\title{
Yield Stability of Very Early Rice Genotypes Under Rainfed Upland Ecosystem
}

\author{
Ashok Mishra ${ }^{1 *}$, Meera Kar ${ }^{2}$ and Padmini Swain ${ }^{2}$ \\ ${ }^{1}$ AICRP for Dryland Agriculture, OUAT, India \\ ${ }^{2}$ ICAR-National Rice Research Institute, Cuttack, Odisha
}

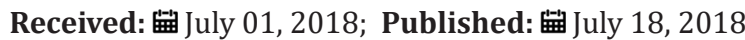

*Corresponding author: Ashok Mishra, Breeder and Officer-in-charge, AICRP on Potato, Directorate of Research, AICRP for Dryland Agriculture, OUAT, Bhubaneswar-751003, Odisha, India

\begin{abstract}
A field experiment was carried out at All India Coordinated Research Project for Dryland Agriculture, Orissa University of Agriculture and Technology, Phulbani to evaluate the newly developed early maturing rice genotypes and estimate their yield stability. The trial was laid out in randomized block design with three replications for 5 years from 2012 to 2016 involving 26 rice genotypes including-(a) 22 improved lines from AICRP for Dryland Agriculture, OUAT, Phulbani (ODR lines; ODR denotes 'Odisha dryland rice'), (b) one line from NRRI sub-centre, Hazaribag, DDR-121, (c) one exotic variety, ZHU 11-26 and (iv) two varieties from NRRI, Cuttack, Vandana and N-22. Another set of experiment was carried out at ICAR-National Rice Research Institute, Cuttack to evaluate the response of the genotypes towards drought stress. Highest mean grain yield was recorded in ODR 12-3 (30.43 q/ha) followed by ODR 12C (27.42 q/ha) and ODR 41 (27.22 q/ha). ODR 12C exhibiting high mean yield along with highest slope can be considered most adaptable. Long slender aromatic genotypes such as ODR 1, ODR 1-1, ODR 1-2 and ODR 1-3 had also high yield coupled with slope $>1.0$, thus exhibited high stability. Drought score (DS), performed on the basis of Standard Evaluation System (SES) scale, showed that ODR-55(1) is highly drought tolerant on the basis of leaf rolling and drying character (SES=0).
\end{abstract}

Keywords: Rice; Rainfed; Drought score; Yield stability

\section{Introduction}

Rice is the staple food for over $90 \%$ population of the Asiatic countries. It is the principal source of energy for the people of Asia, Latin America and pacific islands [1]. It has a distinct position among cereal crops due to its capacity for being cooked and consumed as whole grains [2] and quality assumes great significance. It is also the source of livelihood for a majority of people of India, China and some other countries. Rice cultivation is one of the major providers of rural employment. However, shortage of water in many rices growing countries of the world is gradually increasing with simultaneous decrease in crop yield [3]. Upland rice, covering over 9 million hectares in Asia, is subjected to multiple abiotic stresses, drought being the number one, occurring almost regularly, limiting crop productivity and farmers' income. In this context, increasing productivity of rice in all eco-systems assumes a great challenge as one-sixth of the global population is deprived of enough food and remains hungry or under-nourished.

Since the commencement of green revolution during late 1960s, rice production in India has become trebled and it is important to maintain the increasing trend in future. However, rice cultivation is considered non-remunerative in many parts of India particularly in rainfed uplands due to frequent crop failure during long dry spells.
Still then, in several locations of the states like Odisha, West Bengal, Chhatisgarh, etc. people are reluctant for crop diversification in uplands during kharif (S-W monsoon) season and traditionally grow rice. Many farmers use local short durational rice varieties which mature in 80-90 days and escape terminal drought. In years with early or mid-season drought, these varieties fail to give satisfactory yield. Again, long slender scented rice varieties which could fetch high market price are not available for upland situation.

Rice is the main crop of Odisha including hilly districts like Kandhamal and is grown in all types of land. In Kandhamal district, $80 \%$ of the cultivated area is upland without irrigation facility where only short durational drought tolerant/escaping genotypes can be grown. The productivity of local variety is low. In N-E ghat zone of Orissa, the annual rainfall is quite high (above $1400 \mathrm{~mm}$ ), but the distribution is quite erratic and dependable monsoon occurs only for 3 months. Due to sandy/sandy-loam soil texture in uplands, rice crop suffers severely from dryspells lasting for a week. Again, the yield and quality of local type of rice grown in uplands of Kandhamal is not so good from marketing point of view. Thus, availability of short durational, drought tolerant, high yielding and good quality rice variety which will be acceptable by the farmers is 
needed to increase the net income. Therefore, crop improvement programmes were initiated at All India Coordinated Research Project for Dryland Agriculture from 2006-07 to develop suitable rice varieties for rainfed upland system. The present investigation highlights the yield stability of twenty-six rice genotypes suitable for upland with required features like 1. Short duration, 2. Long slender aromatic grain (Basmati type), 3. High yield, 4. Drought tolerance, and/or 5. Disease pest resistance in order to assure high and stable yield as well as better price for the produce.

Table 1: Rainfall at Experimental site with dry spells.

\section{Materials and Methods}

Site description: The soil at the experimental site had Sandyloam Texture with $\mathrm{pH} 5.22$ and average $\mathrm{N}, \mathrm{P}_{2} \mathrm{O}_{5}$ and $\mathrm{K}_{2} \mathrm{O}$ content of $123,32.1$ and $164.9 \mathrm{~kg} / \mathrm{ha}$, respectively. The normal rainfall of the location is $1407.34 \mathrm{~mm}$. The annual and cropping season rainfall with dry spells affecting growth and productivity at the experimental site in different years has been presented in Table 1.

\begin{tabular}{|c|c|c|c|}
\hline Year & $\begin{array}{l}\text { Annual rainfall } \\
(\mathrm{mm})\end{array}$ & $\begin{array}{l}\text { Crop season rainfall } \\
(\mathbf{m m})\end{array}$ & Periods of dry spells affecting crop growth \\
\hline 2012 & $1695.6 \mathrm{~mm}$ & $1250 \mathrm{~mm}$ & $\begin{array}{l}\text { No rainfall from 24th Sep. to 1st Oct. coinciding with flowering or maturity stage of different } \\
\text { varieties }\end{array}$ \\
\hline 2013 & $1363.4 \mathrm{~mm}$ & 597.8 to $792.6 \mathrm{~mm}$ & $\begin{array}{l}\text { Dryspells from } 2-5 \text { Aug. ( } 4 \text { days), } 14-18 \text { Aug. ( } 5 \text { days), } 22-26 \text { Aug. ( } 5 \text { days), } 30 \text { Aug.-8 Sep. } \\
\text { (10 days), 10-14 Sep. ( } 5 \text { days), 23-27 Sep. ( } 5 \text { days) and, } 4-11 \text { Oct. ( } 8 \text { days) coinciding with } \\
\text { tillering, flowering, milking and dough stages }\end{array}$ \\
\hline 2014 & $1569.3 \mathrm{~mm}$ & $\begin{array}{l}1235.9 \mathrm{~mm} \text { to } 1338.9 \\
\mathrm{~mm}\end{array}$ & $\begin{array}{l}\text { Dryspells from } 28-31 \text { June ( } 4 \text { days), } 16-19 \text { September ( } 4 \text { days) and } 1-11 \text { October ( } 12 \text { days). } \\
\text { Scanty rainfall from } 22 \text { June to } 10 \text { July severely affected germination and seedling growth. }\end{array}$ \\
\hline 2015 & $998 \mathrm{~mm}$ & 490.8 to $637.8 \mathrm{~mm}$ & $\begin{array}{c}\text { Dryspells from 4-8 July, } 12-21 \text { July, 4-7 August, 9-13 August, 2-12 September and no rainfall } \\
\text { after } 22 \text { September coinciding with the initial growth, tillering, flowering, milking and } \\
\text { dough stages of different genotypes }\end{array}$ \\
\hline 2016 & $1248.8 \mathrm{~mm}$ & 959.1 to $967.9 \mathrm{~mm}$ & $\begin{array}{l}\text { Dryspells from 19-27 July, } 19 \text { August-1 September, } 18 \text { September- } 5 \text { October coinciding } \\
\text { with the tillering, flowering, milking and dough stages of different genotypes }\end{array}$ \\
\hline
\end{tabular}

\section{Planting material}

Twenty-six rice genotypes including 22 improved lines from AICRP for Dryland Agriculture, OUAT, Phulbani (ODR lines; ODR denotes 'Odisha dryland rice'), one line from NRRI sub-centre, Hazaribag obtained for evaluation during 2004 (DDR-121), one exotic line from Birsa Agriculture University obtained for evaluation during 1990 (ZHU 11-26) and two lines from NRRI, Cuttack (Vandana and N-22) generally considered as drought tolerant checks, were utilized in the present investigation (Table 2). ZHU 11-26 and DDR-121 were parents of ODR lines. Geetanjali, although a parent, was excluded from this study due to medium maturity duration (130 days). It was used in the hybridization programme for transferring the grain characters (long slender aromatic). Pedigree method of breeding was followed to develop ODR lines.

\section{Experimental plan}

The test genotypes were grown under rainfed upland situation during kharif season in the research farm of AICRP for Dryland Agriculture, OUAT, Phulbani for 5 years from 2012 to 2016. The experiment was laid out in randomized block design with three replications. The crop was sown in lines $20 \mathrm{~cm}$ apart during last week of June with a fertilizer dose of 60-30-30 kg N-P $\mathrm{O}_{5}-\mathrm{K}_{2} \mathrm{O}$. Recommended agronomic practices were followed to raise the crop. A separate experiment was conducted at National Rice research Institute, Cuttack during 2016 to elucidate the reaction of genotypes to drought stress under rainout shelter. Data on early vegetative vigour and drought stress at 33 and 44 days after sowing were recorded (Table 2). Drought stress tolerance was measured in 0 -5 scale; $0=$ very high drought tolerance, 1 =high drought tolerance, $3=$ moderate drought tolerance, and $5=$ drought susceptible.

Table 2: Characteristics of rice genotypes under study.

\begin{tabular}{|c|c|c|c|c|c|c|c|c|}
\hline \multirow{2}{*}{ S.N } & \multirow{2}{*}{ Variety } & \multirow{2}{*}{ Source / parentage } & \multirow{2}{*}{$\begin{array}{l}\text { Days to } 50 \% \\
\text { flowering }\end{array}$} & \multirow{2}{*}{$\begin{array}{l}\text { Plant height } \\
\text { (cm) }\end{array}$} & \multirow{2}{*}{ Grain type } & \multirow{2}{*}{$\begin{array}{c}\text { Early } \\
\text { vegetative } \\
\text { vigour }\end{array}$} & \multicolumn{2}{|c|}{ Drought score } \\
\hline & & & & & & & 33 DAS & 44 DAS \\
\hline 1 & ODR-1-3 & Geetanjali × ZHU 11-26 & 62 & 87.2 & LS & 1 & 1 & 3 \\
\hline 2 & ODR-2 & Geetanjali × ZHU 11-26 & 53 & 65 & SS & 1 & 3 & 3 \\
\hline 3 & ODR 24 (1) & Geetanjali $\times$ ZHU 11-26 & 65 & 90.8 & SS & 1 & 3 & 1 \\
\hline 4 & ODR $1-2$ & Geetanjali × ZHU 11-26 & 69 & 89.9 & LS & 1 & 3 & 1 \\
\hline 5 & ODR 12-1 (1) & Geetanjali $\times$ ZHU 11-26 & 69 & 82.2 & LS & 3 & 1 & 1 \\
\hline 6 & ODR 12-1 & Geetanjali $\times$ ZHU 11-26 & 51 & 79 & SS & 1 & 1 & 1 \\
\hline 7 & ODR 1 & Geetanjali × ZHU 11-26 & 63 & 89.7 & LS & 3 & 3 & 3 \\
\hline 8 & ODR 38 & ZHU 11-26 × DDR 121 & 62 & 88.2 & MS & 1 & 1 & 3 \\
\hline 9 & ODR 41 & ZHU $11-26 \times$ DDR 121 & 68 & 80.3 & SS & 1 & 3 & 3 \\
\hline
\end{tabular}




\begin{tabular}{|c|c|c|c|c|c|c|c|c|}
\hline 10 & ODR 17 & Geetanjali × ZHU 11-26 & 65 & 81.2 & SS & 3 & 1 & 1 \\
\hline 11 & ODR 58 & ZHU 11-26 × DDR 121 & 68 & 128.1 & SS & 1 & 3 & 1 \\
\hline 12 & ODR 5 & Geetanjali × ZHU 11-26 & 63 & 66.7 & SS & 1 & 3 & 3 \\
\hline 13 & ODR $55-1$ & ZHU 11-26 × DDR 121 & 58 & 57.2 & MS & 3 & 0 & 0 \\
\hline 14 & ODR 10 & Geetanjali × ZHU 11-26 & 69 & 86.5 & SS & 1 & 3 & 3 \\
\hline 15 & ODR 12C & Geetanjali × ZHU 11-26 & 66 & 79.5 & SS & 3 & 3 & 3 \\
\hline 16 & ODR 12 & Geetanjali × ZHU 11-26 & 58 & 95.4 & LS & 3 & 1 & 1 \\
\hline 17 & ODR 1 (1) & Geetanjali × ZHU 11-26 & 62 & 89.1 & LS & 1 & 3 & 3 \\
\hline 18 & ODR 24 & Geetanjali × ZHU 11-26 & 66 & 91.9 & SS & 1 & 3 & 1 \\
\hline 19 & ODR 59 & ZHU 11-26 × DDR 121 & 61 & 95.1 & MS & 3 & 1 & 1 \\
\hline 20 & ODR 3-14 & Geetanjali × ZHU 11-26 & 53 & 74.5 & SS & 3 & 1 & 1 \\
\hline 21 & ODR $12-3$ & Geetanjali × ZHU 11-26 & 62 & 95.8 & LS & 3 & 3 & 3 \\
\hline 22 & ODR 30 & ZHU 11-26 × DDR 121 & 62 & 132 & SS & 1 & 3 & 3 \\
\hline 23 & DDR 121 & NRRI (Sub-centre), Hazaribag & 63 & 108.3 & MS & 3 & 1 & 3 \\
\hline 24 & Vandana & NRRI, Cuttack & 65 & 91.2 & SS & 3 & 1 & 1 \\
\hline 25 & N- 22 & $\begin{array}{l}\text { Selection from a local land race at } \\
\text { Nagina, U.P. }\end{array}$ & 65 & 90.1 & MS & 3 & 1 & 1 \\
\hline 26 & ZHU- 11- 26 & $\begin{array}{l}\text { An exotic rice variety introduced } \\
\text { into Odisha through AICRP Birsa } \\
\text { Agricultural University, Ranchi } \\
\text { in } 1990\end{array}$ & 58 & 88.2 & MS & 3 & 1 & 1 \\
\hline
\end{tabular}

\section{Data analysis}

The grain yield data over five years was utilized for stability analysis following Finlay Wilkinson model (1963) [4] using PB Tools, version 1.4. 2014 developed by IRRI, Philippines [5]. As per this model, slope of the regression is a measure for adaptability. The average slope equals unity, indicating average adaptability; genotypes with slopes $>1.0$ have higher than average adaptability (with greater resistance to environmental changes); and genotypes with slopes $<1.0$ have lower than average adaptability.

\section{Results and Discussion}

Drought is a serious abiotic stress for rice production and many popular varieties are drought susceptible [6]. Research on quantitative trait loci (QTL) conferring drought tolerance show that QTLs, primarily contributing towards stable yield under drought stress directly or via secondary traits such as root characteristics and leaf rolling, have relatively small effects and different QTLs have been detected in different studies $[7,8]$. Some QTLs help in significantly increasing water uptake under drought stress and stabilize grain yield $[9,10]$. Attempts have been taken to identify such useful QTLs in crosses involving popular varieties like Swarna to increase their potential for cultivation in drought-prone environments [11]. Among different genotypes, ODR 12-1 took minimum number of days to $50 \%$ flowering closely followed by ODR-2 and ODR-3-14 (Table 2). Three genotypes flowered within 55 days, three between 55-60 days, 13 genotypes between 6065 days, and rest 7 genotypes between 65-70 days. ODR-1, ODR1-1, ODR-1-2 and ODR-1-3 had long slender grains with aroma, thus expected to fetch better market price. They took less than 65 days for $50 \%$ flowering and possessed high or moderate drought tolerance.

Table 3: Grain yield of new rice genotypes at DLAP (OUAT), Phulbani during kharif, 2012 to 2016.

\begin{tabular}{|c|c|c|c|c|c|c|c|}
\hline \multirow{2}{*}{ S.N } & \multirow{2}{*}{ Variety } & \multicolumn{9}{|c|}{ Grain yield q/ha } \\
\cline { 3 - 8 } & & $\mathbf{2 0 1 2}$ & $\mathbf{2 0 1 3}$ & $\mathbf{2 0 1 4}$ & $\mathbf{2 0 1 5}$ & $\mathbf{2 0 1 6}$ & Mean \\
\hline 1. & ODR-1-3 & 22.37 & 28.80 & 21.07 & 14.99 & 24.41 & 22.33 \\
\hline 2. & ODR-2 & 21.03 & 19.20 & 14.80 & 14.99 & 19.72 & 17.95 \\
\hline 3. & ODR 24 (1) & 25.87 & 33.20 & 23.93 & 21.58 & 23.61 & 25.64 \\
\hline 4. & ODR 1-2 & 22.95 & 31.60 & 18.47 & 17.61 & 24.06 & 22.94 \\
\hline 5. & ODR 12-1 (1) & 25.17 & 33.20 & 22.20 & 15.96 & 23.36 & 23.98 \\
\hline 6. & ODR 12-1 & 23.30 & 22.08 & 19.53 & 15.50 & 20.47 & 20.18 \\
\hline 7. & ODR 1 & 24.45 & 28.08 & 21.87 & 18.84 & 22.66 & 23.18 \\
\hline 8. & ODR 38 & 20.18 & 22.56 & 16.33 & 15.53 & 21.60 & 19.24 \\
\hline
\end{tabular}




\begin{tabular}{|c|c|c|c|c|c|c|c|}
\hline 9. & ODR 41 & 25.62 & 34.00 & 25.73 & 24.08 & 26.69 & 27.22 \\
\hline 10. & ODR 17 & 17.92 & 19.80 & 13.40 & 13.56 & 17.40 & 16.42 \\
\hline 11. & ODR 58 & 20.50 & 24.80 & 17.47 & 11.20 & 19.32 & 18.66 \\
\hline 12. & ODR 5 & 18.43 & 27.60 & 22.80 & 13.41 & 20.07 & 20.46 \\
\hline 13. & ODR $55-1$ & 23.44 & 25.40 & 33.00 & 21.23 & 25.85 & 25.78 \\
\hline 14. & ODR 10 & 16.06 & 17.92 & 18.53 & 13.11 & 20.53 & 17.23 \\
\hline 15. & ODR 12C & 27.68 & 36.80 & 32.67 & 14.99 & 24.98 & 27.42 \\
\hline 16. & ODR 12 & 26.52 & 33.12 & 24.20 & 16.91 & 24.96 & 25.14 \\
\hline 17. & ODR 1 (1) & 23.11 & 29.50 & 25.33 & 19.61 & 23.18 & 24.15 \\
\hline 18. & ODR 24 & 26.92 & 33.20 & 27.20 & 21.68 & 25.80 & 26.96 \\
\hline 19. & ODR 59 & 17.21 & 16.80 & 17.60 & 20.39 & 18.05 & 18.01 \\
\hline 20 & ODR 3-14 & 15.21 & 18.00 & 21.00 & 12.60 & 23.00 & 17.96 \\
\hline 21 & ODR $12-3$ & 28.53 & 35.60 & 29.80 & 31.51 & 26.70 & 30.43 \\
\hline 22. & ODR 30 & 24.10 & 28.80 & 21.40 & 20.90 & 19.40 & 22.92 \\
\hline 23. & DDR 121 & 20.58 & 24.40 & 20.07 & 12.36 & 21.00 & 19.68 \\
\hline 24. & Vandana & 22.08 & 26.90 & 19.20 & 21.11 & 23.72 & 22.60 \\
\hline 25. & N- 22 & 14.58 & 14.58 & 11.51 & 14.46 & 17.91 & 14.61 \\
\hline 26. & ZHU- $11-26$ & 16.88 & 28.40 & 17.66 & 20.90 & 23.54 & 21.48 \\
\hline Mean & 21.95 & 26.71 & 21.41 & 17.65 & 22.38 & & \\
\hline $\mathrm{SE}(+\mathrm{m})$ & 0.63 & 0.86 & 0.72 & 0.72 & 0.67 & & \\
\hline $\mathrm{CD}(0.05)$ & 1.84 & 2.49 & 2.09 & 2.09 & 1.96 & & \\
\hline CV (\%) & 4.07 & 4.53 & 4.73 & 5.75 & 4.25 & & \\
\hline
\end{tabular}

Table 4: Stability parameters based on Finlay-Wilkinson Model.

\begin{tabular}{|c|c|c|c|c|c|c|c|}
\hline S.N & Variety & Slope & SE & t.value & Prob & MSReg & MSDev \\
\hline 1 & ODR-1-3 & $1.538^{*}$ & 0.164 & 9.337 & 0.0026 & 98.27 & 1.127 \\
\hline 2 & ODR-2 & 0.508 & 0.421 & 1.206 & 0.314 & 10.736 & 7.377 \\
\hline 3 & ODR 24 (1) & $1.287^{*}$ & 0.31 & 4.151 & 0.025 & 68.765 & 3.99 \\
\hline 4 & ODR 1-2 & $1.613^{*}$ & 0.366 & 4.411 & 0.022 & 107.991 & 5.55 \\
\hline 5 & ODR 12-1 1) & $1.902^{*}$ & 0.18 & 10.551 & 0.002 & 150.254 & 1.35 \\
\hline 6 & ODR 12-1 & 0.713 & 0.343 & 2.081 & 0.129 & 21.121 & 4.877 \\
\hline 7 & ODR 1 & $1.022^{*}$ & 0.158 & 6.479 & 0.007 & 43.347 & 1.033 \\
\hline 8 & ODR 38 & 0.826 & 0.302 & 2.736 & 0.072 & 28.345 & 3.788 \\
\hline 9 & ODR 41 & $1.115^{*}$ & 0.273 & 4.088 & 0.026 & 51.628 & 3.089 \\
\hline 10 & ODR 17 & 0.732 & 0.279 & 2.628 & 0.078 & 22.263 & 3.224 \\
\hline 11 & ODR 58 & $1.497^{*}$ & 0.21 & 7.128 & 0.006 & 93.086 & 1.832 \\
\hline 12 & ODR 5 & $1.513^{*}$ & 0.351 & 4.305 & 0.023 & 95.045 & 5.128 \\
\hline 13 & ODR 55 -1 & 0.335 & 0.77 & 0.435 & 0.693 & 4.653 & 24.601 \\
\hline 14 & ODR 10 & 0.523 & 0.401 & 1.304 & 0.283 & 11.351 & 6.672 \\
\hline 15 & ODR 12C & $2.267^{*}$ & 0.709 & 3.197 & 0.049 & 213.435 & 20.879 \\
\hline 16 & ODR 12 & $1.776^{*}$ & 0.163 & 10.902 & 0.002 & 130.929 & 1.102 \\
\hline 17 & ODR 1 1) & $1.057^{*}$ & 0.224 & 4.718 & 0.018 & 46.405 & 2.084 \\
\hline
\end{tabular}




\begin{tabular}{|c|c|c|c|c|c|c|c|}
\hline 18 & ODR 24 & $1.246^{*}$ & 0.174 & 7.156 & 0.006 & 64.445 & 1.259 \\
\hline 19 & ODR 59 & -0.379 & 0.126 & -3.015 & 0.057 & 5.968 & 0.657 \\
\hline 20 & ODR 3-14 & 0.572 & 0.678 & 0.844 & 0.461 & 13.605 & 19.111 \\
\hline 21 & ODR 12-3 & 0.45 & 0.548 & 0.821 & 0.472 & 8.398 & 12.472 \\
\hline 22 & ODR 30 & 0.865 & 0.436 & 1.986 & 0.141 & 31.097 & 7.883 \\
\hline 23 & DDR 121 & $1.307^{*}$ & 0.248 & 5.268 & 0.013 & 70.888 & 2.555 \\
\hline 24 & Vandana & 0.702 & 0.327 & 2.148 & 0.121 & 20.47 & 4.438 \\
\hline 25 & N-22 & 0.086 & 0.403 & 0.215 & 0.844 & 0.31 & 6.738 \\
\hline 26 & ZHU-11-26 & 0.923 & 0.651 & 1.418 & 0.251 & 35.402 & 17.598 \\
\hline
\end{tabular}

The plant height of different genotypes varied from $57.2 \mathrm{~cm}$ in ODR 55-1 to $132 \mathrm{~cm}$ in ODR-30. All genotypes had slender grains and were grouped into three categories, such as long slender (LS), medium slender (MS) and short slender (SS). In spite of quite sufficient crop seasonal rainfall in several years, the distribution was erratic with dry spells at critical growth stages that could affect the crop growth and productivity. Significant variation was observed among the test genotypes for grain yield in all the five years (Table 3). Highest mean grain yield was recorded in ODR 12-3 (30.43q/ha) followed by ODR 12C (27.42q/ha) and ODR 41 (27.22q/ha). ODR 12C exhibiting high mean yield along with highest slope (Table 4) can be considered most adaptable. Long slender aromatic genotypes such as ODR 1, ODR 1-1, ODR 1-2 and ODR 1-3 had also high yield coupled with slope $>1.0$, thus exhibited high stability. Under rainfed upland ecosystem, availability of such high-quality genotypes seems to enhance profitability of rice farming particularly of tribals in hilly tracts. Among these 4 types, ODR 1-2 had high drought tolerance at 44 days after sowing under rain out shelter situation and thus could be advocated for drought prone areas. All other genotypes having comparatively higher grain yield and slope > 1.0 may also be recommended for rainfed uplands.

A crop like rainfed (kharif) rice is more sensitive to rainfall than temperature. In future, water availability is likely to be reduced and soils of high water holding capacity [12] and use of drought tolerant varieties may play an important role in maintaining crop yield. Drought score (DS), performed on the basis of Standard Evaluation System (SES) scale, showed that ODR-55(1) is highly drought tolerant on the basis of leaf rolling and drying character (SES ' 0 '). Since the phenotypic performance of a variety may not be same under different agro-ecological situations due to the influence of environment on genotype, information on phenotypic stability holds a great promise. Stability of a variety enables it to remain unaffected by environmental changes [13]. The aromatic long slender rice genotypes are expected to increase the net income of farmers due to high market price of the produce. Almost 100 volatile compounds have been reported to be responsible for basmati flavor which includes 13 hydrocarbons, 14 organic acids, 13 alcohols, 16 aldehydes, 14 ketones, 8 esters, 5 phenols, etc. $[14,15]$. The principal compound responsible for aroma, 2-Acetyl- 1-pyrroline (2AP), has been detected in the whole above ground plant parts of scented rice $[16,17]$. In addition to $2 \mathrm{AP}$, several other volatile compounds contributing to the aroma of scented rice cultivars, such as hexanal, nonanal, octanal, decanal, guaicol, indole and vanillin, have been identified $[18,19]$. Even in absence of the estimates on aroma, the aromatic long slender genotypes used in the present study with high drought tolerance and stability need attention for rapid spread across locations.

\section{Conclusion}

The present investigation highlights the stability of new rice genotypes varying in grain type, aroma, duration and grain yield to justify their suitability for cultivation in rainfed uplands. The genotypes exhibiting 50\% flowering within 55 days are expected to escape drought, frequently occurring towards end of monsoon season although they may not possess adequate drought tolerance. The genotypes with high mean grain yield, slope $>1.0$ and good grain quality like ODR 1-2 are to be adopted for rainfed upland conditions of Odisha in order to improve the economic condition of rice farmers.

\section{References}

1. Hu P, Zhao H, Duan Z, Linlin Z, Wu D (2004) Starch digestibility and the estimated glycemic score of different types of rice differing in amylose contents. Journal of Cereal Science 40(3): 231-237.

2. Hossain MS, Singh AK, Fasih uz Zaman (2009) Cooking and eating characteristics of some newly identified inter sub-specific (indica/ japonica) rice hybrids. Science Asia 35: 320-325.

3. Rosegrant MW, Cline SA (2003) Global food security: challenges and policies. Science 302(5652): 1917-1919.

4. Finlay KW, Wilkinson GN (1963) The analysis of adaptation in a Plant Breeding Programme. Australian Journal of Agricultural Research. 14(6): 742-754.

5. PB Tools (2014) Biometrics and Breeding Informatics, PBGB Division, International Rice Research Institute. Los Baños, Laguna, Philippines.

6. Serraj R, Kumar A, McNally KL, Slamet Loedin I, Bruskiewich R, Mauleon $R$ (2009) Improvement of drought resistance in rice. Adv Agron 103: 4199.

7. Lafitte HR, Ismail AM, Bennett J (2006) Abiotic stress tolerance in tropical rice: progress and future prospects. Oryza 43(3): 171-186.

8. Bernier J, Atlin GN, Serraj R, Kumar A, Spaner D (2008) Breeding upland rice for drought resistance. J Sci Food Agric 88: 927-939. 
9. Bernier J, Kumar A, Ramaiah V, Spaner D, Atlin G (2007) A large-effect QTL for grain yield under reproductive-stage drought stress in upland rice. Crop Sci. 47(2): 507-518.

10. Bernier J, Serraj R, Kumar A, Venuprasad R, Impa S, et al. (2009) The large-effect drought-resistance QTL qtl12.1 increases water uptake in upland rice. Field Crops Res 110: 139-146.

11. Venuprasad R, Dalid CO, Del Valle M, Zhao D, Espiritu M, et al. (2009) Identification and characterization of large-effect quantitative trait loci for grain yield under lowland drought stress in rice using bulk-segregant analysis. Theor Appl Genet 120(1): 177-190.

12. Kang Yinhong, Khan Shahbaz, Xiaoyi Ma (2009) Climate change impacts on crop yield, crop water productivity and food security - A review. Progress in Natural Science 19(12): 1665-1674.

13. Allard R W and Bradshaw AD (1964) Implications of GenotypeEnvironmental Interactions in Applied Plant Breeding. Crop Science 4: 503-508.

14. Hussain AA, Maurya DM, Vaish CP (1987) Studies on quality status of indigenous upland rice. (Oryza Sativa). Indian J Genet Pl Breed 47(2): 145-152.
15. Hussain A, Naqvi SHM, Hammerschimdt FJ (1987) Isolation and identification of volatile compo- nents from Basmati rice (Oryza sativa L) In: Martens M, Dalen GA, Russwurm H, editors. Flavor Sci Tech Wiley. pp. 95-100.

16. Yoshihashi T, Huong NTT, Inatomi H (2002) Precursors of 2-acetyl-1pyrroline, a potent flavor compound of an aromatic rice variety. J Agric Food Chem 50(7): 2001-2004.

17. Maraval I, Sen K, Agrebi A (2010) Quantification of 2-acetyl-1-pyrroline in rice by stable isotope dilution assay through headspace solidphase microextraction coupled to gas chromatography-tandem mass spectrometry. Anal Chim Acta 675(2): 148-155.

18. Mathure SV, Wakte KV, Jawali N, Nadaf AB (2011) Quantification of 2-Acetyl-1-pyrroline and Other Rice Aroma Volatiles Among Indian Scented Rice Cultivars by HS-SPME/GC-FID. Food Anal Methods 4(3): 326-333.

19. Mathure SV, Jawali N, Thengane RJ, Nadaf AB (2014) Comparative quantitative analysis of headspace volatiles and their association with BADH2 marker in non-basmati scented, basmati and non-scented rice (Oryza sativa L.) cultivars of India. Food Chem 142: 383-391.

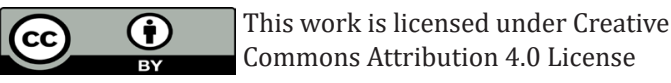

To Submit Your Article Click Here: Submit Article
DOI: 10.32474/CIACR.2018.03.000171

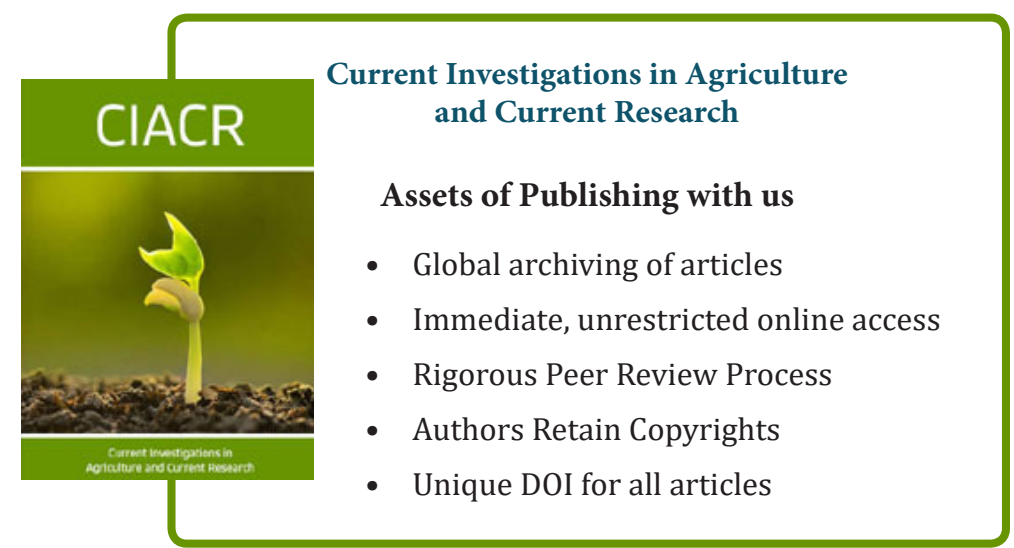

